\title{
OS ESPORTES DOS IMIGRANTES JAPONESES NO JORNAL DE NOTÍCIAS E SUAS RELAÇÕES COM A IDENTIDADE NACIONAL (1947-1950)
}

Recebido em: 09/03/2018

Aceito em: 22/09/2018

\author{
Igor Cavalcante Doi ${ }^{1}$ \\ Edivaldo Góis Junior ${ }^{2}$ \\ Universidade Estadual de Campinas (UNICAMP) \\ Campinas - SP - Brasil
}

RESUMO: Esta pesquisa pretendeu explorar os discursos da imprensa paulista, especialmente o Jornal de Notícias, a respeito das práticas de lazer físico/esportivo nas quais se engajavam os imigrantes japoneses após a Segunda Guerra, buscando possíveis relações entre essas práticas e a identidade nacional desse grupo. As matérias jornalísticas foram coletadas na Hemeroteca Digital da Biblioteca Nacional, entre 1947 e 1950, período de grande fervor do nacionalismo japonês no Brasil. Como resultado, o estudo contribui para a construção de uma história do lazer tanto na imprensa brasileira como no contexto das imigrações para o Brasil, revelando as práticas esportivas de imigrantes que despontavam na paisagem nacional e como eram tratadas por parte da imprensa. Sobre a relação de tais práticas com a identidade japonesa, as fontes apontam para a plausibilidade da hipótese, requerendo o acúmulo de mais estudos sobre o tema.

PALAVRAS CHAVE: Emigrantes e Imigrantes. Esportes. Identidade Nacional.

\section{JAPANESE IMMIGRANTS SPORTS IN THE JORNAL DE NOTÍCIAS NEWSPAPER AND ITS RELATION TO NATIONAL IDENTITY (1947-1950)}

ABSTRACT: This research aimed to explore the discourses in São Paulo's press especially the Jornal de Notícias newspaper - about the physical/sportive leisure practices in which Japanese immigrants engaged after the Second World War, searching for possible relations between those practices and the national identity of that group. The newspaper stories, dated between 1947 and 1950, a period of great fervor Japanese nationalism in Brazil, were collected on the Brazilian National Library digital archives. As a result, this work contributes to the construction of a history of leisure in the Brazilian press, as well as

\footnotetext{
${ }^{1}$ Graduado em Educação Física. Mestrando em Educação Física e Sociedade na Faculdade de Educação Física da Unicamp. Membro dos grupos de pesquisa "Corpo e Educação" e "MARGEM".

${ }^{2}$ Doutor em Educação Física pela Universidade Gama Filho. Professor no Departamento de Educação Física e Humanidades da UNICAMP. Professor e coordenador do Programa de Pós-Graduação em Educação Física da Unicamp. Líder dos grupos de pesquisa "Corpo e Educação" e "MARGEM".
} 
in the context of immigration in Brazil, revealing the sport practices of immigrants that were visible in the national landscape, and how some sects of the press represented them. About the relations of such practices with Japanese identity, the sources point to the plausibility of this hypothesis, but further accumulation of studies about this theme is required.

KEYWORDS: Emigrants and Immigrants. Sports. National Identity.

\section{Introdução}

Sabe-se que, ao translocar-se para longe da terra natal, os imigrantes tendem a levar consigo não apenas seus pertences, mas também seus hábitos, sua língua, seu conhecimento sobre o mundo, enfim, sua cultura. E, dentre tantos produtos da tradição de um povo, destacam-se, para nós, os usos dos corpos, os quais, como as outras práticas culturais, frequentemente se deslocam com a população imigrante. Dentre esses usos dos corpos, esta pesquisa se interessa especificamente pelos esportes, entendidos como práticas eminentemente culturais. Em vista disso, no âmbito dessa relação entre esportes e cultura em que se fundam essas práticas, o presente estudo pretende pensar as relações entre práticas de lazer físico-esportivas e identidades em populações imigrantes, considerando um tipo específico de identidade: a identidade nacional - entendendo que identificar-se com uma nação significa imaginar-se como parte de uma comunidade limitada, livre e soberana, como se pode deduzir do conceito de nação desenvolvido por Benedict Anderson (2008).

Algumas pesquisas têm se debruçado sobre a relação entre esportes e identidade nacional (CAPISTEGUI, 2012). Lin e Lee (2007), por exemplo, investigaram o beisebol como um dos meios de demarcação identitária contra a intenção assimilacionista dos colonizadores japoneses em Taiwan, enquanto Bairner e Hwang (2010) propuseram que disputas políticas e identitárias entre Taiwan e a China continental também se deram no 
âmbito esportivo, após a tomada de Taiwan pelo Kuomitang. Para além do esporte moderno em seu entendimento mais estrito, podemos encontrar trabalhos que relacionam identidade nacional e artes marciais, como é o caso do estudo de Johnson (2012), que narra como o Karatê okinawano tornou-se uma prática corporal "japonesa" apenas no século XX. Outras pesquisas têm se debruçado sobre esporte e identidade centrando-se especificamente em grupos de imigrantes, como Blecking (2008), que estudou a importância das associações esportivas para a coesão interna de dois grupos imigrantes na Alemanha: os poloneses e os turcos; Bunk (2015), por sua vez, abordou a Liga Hispano Americana de Balonpié nos Estados Unidos como palco de tensões identitárias a níveis nacional e regional, assim como no universo linguístico; já a importância da Gaelic Athletic Association nos Estados Unidos para a preservação da identidade irlandesa foi estudada por Darby (2006; 2010a; 2010b).

No Brasil, a possibilidade de se relacionar as práticas esportivas, o associativismo esportivo e as identidades de imigrantes têm sido exploradas por alguns trabalhos, como o de Silva; Pereira e Mazo (2012), que discorrem sobre as negociações identitárias através dos clubes esportivos de imigrantes alemães e portugueses no Rio Grande do Sul. Silva e colaboradores (2016) também estudaram como uma identidade teuto-brasileira foi negociada em agremiações esportivas no decorrer da Primeira Guerra Mundial em Porto Alegre. Ainda sobre os imigrantes alemães, Quitzau e Soares (2010, p.91) pontuam que

\footnotetext{
Buscando manter essas tradições e esses costumes, os imigrantes alemães fundaram diversas associações educacionais, religiosas, de auxílio e recreativas, onde tinham como objetivo propiciar aos seus descendentes de sangue alemão a oportunidade de crescerem, serem educados e criados conforme as tradições germânicas, dentre as quais podemos destacar a prática da ginástica.
} 
Intentando contribuir para a exploração desse tema, conjugando esportes, identidade nacional e imigração, esta pesquisa investiga as relações entre esportes e identidade nacional no contexto específico da imigração japonesa em São Paulo.

Foi durante os últimos anos do Estado Novo, que mesclaram uma pressão nacionalizadora sobre os imigrantes japoneses e uma guerra mundial em que o seu país de origem se encontrava fortemente envolvido, que o sentimento de japonidade começou a se inflamar na colônia. Sociedades secretas nacionalistas começaram a surgir, como a Kodosha e a Shindo-Renmei, e foram protagonistas de diversos casos de ameaças, sabotagens e assassinatos de seus próprios patrícios.

Em 1945, quando o Japão assinou seu termo de rendição da Segunda Guerra, grande parte dos colonos japoneses no Brasil não acreditou na notícia e passou-se a perseguir aqueles que seriam chamados de "derrotistas" - que acreditavam na derrota de seu país. É nesse contexto, de pós-Guerra e de inflamação da identidade nacional entre os imigrantes japoneses, que nós nos perguntamos se as práticas de lazer esportivas teriam desempenhado algum papel na manutenção e no fortalecimento dessa identidade em São Paulo.

Como recurso metodológico, optamos por uma abordagem historiográfica particularmente próxima à História Cultural. Isto é dizer que a pesquisa busca uma relação entre práticas culturais e suas representações, o que, para Burke (2005) constitui o novo paradigma de pesquisa desse ramo da História. Como apontou Chartier (1988), falar em práticas e representações é efetuar um retorno à sociologia francesa para a busca de um aporte teórico que por muitas vezes faltou à Histórica cultural. Nessa tradição sociológica que buscamos, entende-se que "não há representação que não tenha, em certo grau, uma 
repercussão sobre a ação e que não há ação pura" (MAUSS, 1999, p.67) ${ }^{3}$. Com isso, é possível inferir que a prática corporal ${ }^{4}-$ e o esporte, como subconjunto -, esse ato social, não pode ser vazio de representações, devendo expressar, no seu desenvolvimento, o imaginário social de sua época, do grupo que o exerce e os conflitos que nele encerra. É precisamente desse ponto que parte a conjectura de que os esportes, como prática, podem possuir relações com as representações de nação expressas em discursos. Partido dessa perspectiva foi que procedemos constituindo um corpo documental a partir dos jornais no acervo digital da Biblioteca Nacional. Foram coletadas 340 matérias jornalísticas ${ }^{5}$ nos seguintes veículos paulistas: Mundo Esportivo, Cine Repórter, Moscardo, e Jornal de Notícias, que foram filtradas para conter apenas artigos que fizessem menção a práticas corporais e que tivessem relação com a colônia japonesa. Horários de competições e tabelas de resultados publicados nos jornais também não eram do interesse desta pesquisa e foram excluídos. Ao final, nossa amostra contou com 18 documentos do Jornal de Notícias, todos eles sobre práticas esportivas, especificamente, o que fez desta pesquisa um estudo com enfoque no esporte ${ }^{6}$.

O recorte temporal foi delimitado inicialmente pelo ano de 1945, ano da rendição do Japão, quando começa o conflito entre "vitoristas" e "derrotistas", e 1950, ano em que se

\footnotetext{
${ }^{3}$ Segundo Evans-Pritchard (1978), representações coletivas é um termo caro à sociologia francesa e que pode significar um conjunto de ideias, noções ou crenças, que é compartilhado por todos ou quase todos num grupo social.

${ }^{4}$ Há também uma reflexão sobre a noção de prática corporal em Silva (2014), embora aqui a minha aproximação seja pela noção sociológica de prática cultural.

5 Muitos termos de busca foram utilizados, mas, desses, apenas "japoneses" produziu resultados significativos.

${ }^{6}$ Para esclarecer, a pesquisa se propunha a investigar práticas corporais diversas, como danças, artes marciais, etc., mas a busca nos devolveu apenas respostas sobre esportes. Como entendemos o esporte também como prática corporal, o termo "práticas corporais" pode aparecer eventualmente em lugar de "esportes" ao longo do texto. E, sendo o esporte praticado no tempo livre, pode também aparecer como "prática de lazer esportivo".
} 
tem o último registro na literatura da maior associação nacionalista de imigrantes japoneses, o que, para nós, marca o declínio da ebulição nacionalista da comunidade japonesa. Foi interessante notar, contudo, que há um silêncio da imprensa paulista em relação a práticas corporais entre imigrantes japoneses nos anos 1945 e 1946, fazendo com que os nossos recortes mais antigos sejam datados, na verdade, de 1947.

Ao fim da pesquisa, pudemos narrar uma história sobre os esportes dos imigrantes japoneses e fazer inferências sobre as relações entre práticas de lazer esportivas e identidade nacional a partir do material empírico. Para caminharmos até isso, convém começarmos por investigar as questões concernentes à identidade nacional japonesa no Brasil, que foi alavancada pela Segunda Guerra e a formação de associações nacionalistas. Como veremos, a comunidade japonesa elaborou critérios de aceitação dos indivíduos na categoria de japoneses, que envolviam a devoção ao imperador, o vitorismo e o apoio ao expansionismo do Japão. Essa breve investigação nos proverá o contexto de nacionalismo em que as práticas de lazer esportivas se manifestavam.

\section{A Identidade dos Imigrantes Japoneses e as Sociedades Secretas}

Sabemos que um dos maiores entraves para a imigração japonesa - do ponto de vista dos seus anfitriões - foi a consideração de que se tratava de uma população de inassimiláveis. Em decorrência de uma crescente ebulição do espírito nacionalista brasileiro na década de 1930, os agrupamentos, chamados de “quistos" étnicos, eram entendidos como uma ameaça à integridade nacional. Como observa Bartolomé (1994), minorias étnicas são um risco para o Estado-nação, pois criam identificações intermediárias entre o indivíduo e o Estado, resultando no enfraquecimento da hegemonia do Estado na 
constituição de representações identitárias absolutas. Uma homogeneidade racial, linguística e nacional era almejada e, devido a isso, segundo Seyferth (1999), no Estado Novo muitas escolas estrangeiras foram fechadas e regras foram impostas para nacionalizar o ensino; o uso de idioma estrangeiro em público foi vetado, inclusive em rituais religiosos; e as colônias passaram a não poder compor-se de apenas uma nacionalidade.

Uma vez que se desenrolava uma campanha de homogeneização nacional, alguns nissei (filhos de imigrantes japoneses) responderam reafirmando sua brasilidade, principalmente através de um novo jornal da Liga Estudantina Nipo-Brasileira, o Transição, cujo título fazia referência a uma identidade hifenizada - a nipo-brasileira (LESSER, 2001). Por outro lado, os imigrantes de primeira geração ainda alimentavam aquela intenção inicial de retornar à pátria. Uma pesquisa de 1939 encontrada por Myiao e Yamashiro (1992) mostrava que 85\% da colônia japonesa da região Noroeste de São Paulo gostariam de regressar ao Japão, contra apenas $10 \%$ que queriam permanência definitiva no Brasil, o que aponta para o fato de que a identidade japonesa prevalecia entre essa categoria de imigrantes, contra a tentativa da inculcação de uma identidade nacional brasileira ou hifenizada.

Em janeiro de 1942, o Brasil rompe relações diplomáticas com os países do Eixo (KOIFMAN; ODA, 2013), agravando a preocupação dos nacionalistas brasileiros em relação aos "quistos" japoneses, que eram vigiados com a desconfiança de que tramavam planos sob o comando do exército japonês. Essas desconfianças tornavam os japoneses potenciais inimigos internos. Para Lesser (2001), houve com isso uma inflação do sentimento de japonidade, o que culminou na formação de sociedades secretas nacionalistas, dentre as quais a Shindo-Renmei, que foi a maior e mais conhecida. A partir 
de então, começam a ser registrados casos de "sabotagem" realizados por nacionalistas japoneses no Brasil contra imigrantes japoneses que produziam seda e menta em solo brasileiro, pois se dizia que o primeiro produto era vendido para a fabricação de paraquedas para os Estados Unidos, enquanto o segundo serviria para produzir óleo de arrefecimento para máquinas aliadas (LESSER, 2001; MIYAO, YAMASHIRO, 1992), o que, evidentemente, contrariava os interesses da sua pátria.

A Kôdôsha, que Miyao e Yamashiro (1992) entendem como precursora da ShindoRenmei, foi outra dessas sociedades secretas. Ela se baseava no que ficou conhecido como "Espírito Kikkawa", fundado num manuscrito de Junji Kikkawa, em que o autor defendia que os filhos de imigrantes japoneses fossem educados para serem nacionalistas, que se sacrificassem pelo Japão e pelo Imperador, e ainda criticava a atitude apática de alguns imigrantes em relação à sua nação, assim como a degenerescência moral que ocorria entre os patrícios no Brasil.

Em maio de 1945, o Brasil declarou guerra ao Japão (BRASIL, 1945). Em agosto do mesmo ano, o Japão se rendeu, acirrando os conflitos dentro da colônia, pois apenas uma pequena parte dos imigrantes japoneses acreditou na derrota de seu país no fim da guerra. Essa recusa a crer na derrota, conhecida como vitorismo, era resultante de uma identidade nacional consolidada sob a influência da educação patriótica no regime Meiji, que havia ensinado a seus súditos que o Imperador era divino e o Japão, por conseguinte, indubitavelmente invencível. Em outras palavras, a identidade nacional japonesa no Brasil era constituída por uma "comunidade imaginada" (ANDERSON, 2008) que estava intimamente ligada à veneração ao Imperador, como mostra o seguinte documento da Shindo-Renmei: 
Pela minha convicção pessoal, o Império existe porque existe S. M. O Imperador e não o contrário, o Imperador existe porque existe o Império Japonês. Mesmo que reste o território nacional, um território sem o Imperador não pode ser chamado de Japão ${ }^{7}$.

Qualquer demonstração de indiferença em relação à pátria e ao Imperador, como no caso dos produtores de seda e menta, e também entre os japoneses esclarecidos ou "derrotistas", furtava do imigrante o seu direito de ser japonês, de pertencer à comunidade imaginada, pois ser japonês era ser súdito do Imperador e compartilhar o espírito expansionista do Hakkô Ichiu (O Mundo sob um Teto). Assim, os "derrotistas", para a sociedade secreta Shindo-Renmei, "são inferiores aos italianos, na verdade não são nipônicos e sim pessoas pertencentes a países inimigos. São traidores da pátria” ${ }^{8}$.

Podemos observar, então, que entre os imigrantes japoneses havia uma disputa pela validade de certas representações do ser japonês, prevalecendo o espírito nacionalista, através do qual muitos deles identificaram-se, nos anos que sucederam o término da Segunda Guerra, como japoneses, súditos do Imperador e vitoristas, sendo que os "derrotistas" e aqueles imigrantes agricultores cuja produção contrariava os interesses do Japão eram entendidos como traidores e, portanto, não japoneses. Esses eram os critérios a partir dos quais, entre os nacionalistas japoneses no Brasil, alguém podia considerar-se de fato nipônico. Aqui, as práticas e os discursos "tendem a impor uma autoridade à custa de outros" e, por isso, a investigação sobre as representações "supõe-nas como estando sempre colocadas num campo de concorrências e de competições cujos desafios se enunciam em termos de poder e de dominação" (CHARTIER, 1988, p. 17).

\footnotetext{
${ }^{7}$ Representação da Shindo-Renmei, do Museu de Imigração, transcrita por Miyao e Yamashiro, 1992, p.286.

${ }^{8}$ Representação da Shindo-Renmei, do Museu de Imigração, transcrita por Miyao e Yamashiro, 1992, p.287, grifos nossos.
} 
É claro que, entre vitoristas fervorosos, de um lado, e derrotistas, de outro, havia, aparentemente, uma ampla ala de imigrantes japoneses que apoiavam as sociedades secretas e suas convicções nacionalistas, mas não participavam do ativismo nacionalista e tampouco geraram grandes conflitos. Ainda é preciso notar que, mesmo entre os mais firmes em seu nacionalismo, nem todos os membros ativos das sociedades secretas eram propensos às atitudes violentas. Mesmo assim, a inscrição de mais de cem mil membros na Shindo-Renmei (Vieira 1973, p.255 apud Dezem, 2000, p.75) denuncia que ela era amplamente apoiada pela colônia japonesa. Essas associações, ao mesmo tempo em que exaltavam a identidade nacional, denunciavam aqueles patrícios que, segundo os nacionalistas japoneses, não eram mais nipônicos, por não se enquadrarem nos critérios de japonidade estabelecidos naquele momento.

Uma vez reconhecida a cena de tal ebulição da identidade dos imigrantes japoneses no pós-Guerra, cuja materialização começa a se dar anos antes ${ }^{9}$, cabe a principal questão deste trabalho: qual teria sido a importância dos esportes na manutenção ou na transformação da identidade dos imigrantes japoneses no pós-Guerra? Como isso teria sido retratado pela imprensa paulista?

\section{Os Esportes da Colônia Japonesa entre 1947 e 1950 no Jornal de Notícias}

O objetivo primeiro desta pesquisa foi formulado no sentido de investigar o problema proposto nos jornais paulistas do período, mas quis o percurso, contra toda

\footnotetext{
${ }^{9}$ O escândalo das sociedades secretas teve início em 1943, "quando um juiz da Segurança Nacional ordenou a prisão de um grupo da cidade de Bastos, acusado de subversão" (LESSER, 2001, p.238); um galpão de bicho da seda foi incendiado em 1944 (DEZEM, 2000); e assassinatos a "derrotistas" iniciaram-se em março de 1946 (DEZEM, 2000).
} 
expectativa que tínhamos, que lidássemos com um único periódico. Isso porque, dentro dos limites existentes nos termos pesquisados no arquivo que consultamos, foi o único a produzir resultados significativos para o que queríamos avaliar. Isso nos diz alguma coisa. Em primeiro lugar que, dentre os jornais disponíveis, este tinha alguma preocupação com as manifestações esportivas que envolviam os imigrantes japoneses. Não se poderia dizer, sem o risco de ser entusiasta em demasia, que essa era uma preocupação especial do jornal, visto que só pudemos colher, numa busca que se estendeu por quase 5 anos de publicações, 18 exemplares de textos em que estavam presentes os esportes e o envolvimento da colônia japonesa ao mesmo tempo. Mas ainda assim se trata de um caso especial. Além da escassez dessas publicações, nos deparamos com o silêncio desse tema até o ano de 1947, quando aparece o primeiro recorte significativo.

Desvendar o jornal, sua história, suas orientações, seus motivos, tudo isso escapa ao escopo desta pesquisa, que é sobre as práticas de lazer físico-esportivo entre os imigrantes japoneses. Uma revisão sobre a história da imprensa no Brasil e em São Paulo foi de pouca ajuda para compreender o Jornal de Notícias, pois seu nome não é citado em nenhuma das obras consultadas (SODRÉ, 1999; BARBOSA, 2007; PILAGALLO, 2012). Usando sistemas de busca integrada em diferentes bases de dados, quase nada foi encontrado sobre sua história e orientações editoriais. Encontramos apenas um trabalho mencionando o jornal, apontando-o como um dos veículos da grande imprensa que, entre 1951 e 1952, foi entusiasta em relação à Lei “Afonso Arinos", a qual condenava as atitudes discriminatórias baseadas em critérios raciais (CAMPOS, 2015). Mesmo assim, quando defendeu sua tese, Campos (2016), após ter discorrido sobre os vários periódicos que consultou, comentou do 
Jornal de Notícias apenas que ele não tem recebido atenção das pesquisas na área. Trata-se, portanto, de um jornal que vem sendo omitido em boa parte das produções historiográficas.

O que sabemos, de nossa busca no acervo, é que se trata de um periódico nascido em 12 de abril de 1946, no município de São Paulo, sob direção de Fernando Marrey e sede na Rua Florencio de Abreu, número 164, onde operava a redação e a oficina. Era propriedade da Companhia Paulista Editora e Jornais S. A. Seus números saíam diariamente (exceto às segundas-feiras) com 8 a 12 páginas, possuindo alguns números especiais que passavam as 20 páginas. Marrey era um homem da indústria e diretor-presidente do Estabelecimento Nacional Indústria de Anilinas S.A. "ENIA" e deixou a direção do jornal na edição seguinte ao anúncio de seu afastamento da diretoria da ENIA (ESTABELECIMENTO..., 1947), legando sua posição no jornal ao jornalista Carlos Laino Júnior, quem assinou a publicação pela primeira vez em 17 de junho de 1947.

O editorial da primeira edição (NOSSO..., 1946) se inicia com uma referência aos conflitos bélicos mundiais recentes e diz haver uma necessidade de solidariedade entre os povos. Com um texto enigmático que indica um contexto ambíguo no qual um passado a ser deixado se mescla com um futuro em construção, coloca-se o jornal como um "éco das aspirações gerais do moderno cosmo social" e questiona tanto o modo doutrinário de jornalismo do século XIX como o "oportunismo neutro e furta-cor em sua impassibilidade calculada". No seu editorial de fechamento, em 10 de novembro de 1951, assinado pela única vez pelo diretor-superintendente Julio Cosi, identifica-se como um periódico de orientação progressista e promete voltar em breve, assim que melhor equipado em suas instalações para competir com a vasta concorrência no mundo da imprensa paulista. Não encontramos nenhum indício de que o periódico tenha de fato retornado à atividade. 
Entre seus diretores, teve também André Carrazzoni (ver A DIREÇÃO..., 1948), entre 14 de outubro de 1948 e 14 de fevereiro de 1948, Galeão Coutinho, de 15 de março de 1951 a 19 de setembro de 1951 e Honório de Sylos (diretor-superintendente), que assinou sozinho as capas de 20 de setembro de 1951 até o penúltimo dia, ${ }^{10} 10$ de novembro de 1951. Outro nome bastante relevante é o de Gladston Jafet, que aparecia como diretorpresidente ao lado do diretor-responsável nas publicações entre 14 de agosto de 1948 e 15 de fevereiro de 1951 e era um membro do Partido Social Progressista, tendo assumido a função de $2^{\circ}$ tesoureiro do partido pelo menos uma vez, quando da reeleição de Adhemar de Barros para a presidência do mesmo (O SR. ADHEMAR... 1947). Em muitas publicações, nomes de diretores não apareciam, privilegiando redatores-chefes como Galeão Coutinho, Wladimir de Toledo Piza e Fernando Góes. Sobre o alcance e a tiragem da publicação, por ora nada pudemos constatar.

Observando os vestígios produzidos pelo Jornal de Notícias, pudemos observar que, no período pós-Guerra, como antes dele, os esportes eram bons mobilizadores da colônia japonesa. O Centro da Nova Juventude Brasileira, uma associação de filhos de japoneses, foi fundado em maio de 1950 com fins culturais e esportivos (O INTERIOR EM REVISTA, 1950), atendendo também a uma tendência desses imigrantes ao associativismo demonstrada por Cardoso (1995). Eventos esportivos de beisebol, natação, atletismo e tênis eram produzidos por ou continham a participação de imigrantes nipônicos. $\mathrm{O}$ beisebol, por exemplo, foi marcadamente um esporte japonês no Brasil, como lembrou Léo Liedke, um filho de imigrantes alemães de Pereira Barreto, SP, que conviveu na juventude com os imigrantes japoneses: "Eu era o único brasileiro que jogava beisebol. Porque o beisebol no

\footnotetext{
${ }^{10}$ Ele já assinava como diretor-superintendente ao lado do diretor-responsável desde bem antes.
} 
Brasil é um esporte praticado por japoneses, né" (ENNES, 2003, p.45). Um não-japonês praticando beisebol era, a partir da fala de Liedke, provavelmente um forasteiro, levando-se em conta que esse esporte era associado a uma nacionalidade específica. $O$ Jornal de Notícias elogiou o empreendimento dos japoneses para a difusão do beisebol no Brasil, salientando que "ninguém fez nada por ele nos primeiros tempos, a não ser os esportistas japoneses, sempre dedicados e batalhadores" (TRABALHA-SE..., 1947). Em 1950, o anúncio do início do "Campeonato Paulista de Basebol" vinha acompanhado da imagem de jogadores de fisionomia asiática e da lista de times participantes, entre os quais o Copercotia possivelmente representava a Cooperativa Agrícola de Cotia, uma associação de imigrantes japoneses (CAMPEONATO..., 1950).

Além do envolvimento com o beisebol, a Cooperativa Agrícola de Cotia também recebeu "licença para promover o seu Campeonato $<<$ Interzonas $>>$, com a participação de tenistas japoneses radicados no Interior", que seria realizado em setembro de 1951 (ATIVIDADES..., 1950). E a colônia japonesa não apenas foi promotora de um evento como esse, como também influenciou o Departamento de Esportes do Estado de São Paulo (DEESP) a convidar atletas dessa modalidade para virem do Japão visitar o Brasil (VAI AO JAPÃO..., 1950).

O atletismo também fez parte da vida esportiva desses imigrantes. Duas reportagens anunciam competições entre os "Novos", da Federação Paulista de Atletismo, e o "Qualquer Classe", que representava a colônia (NOVOS VS. JAPONESES, 1950; JAPONESES VS. NOVOS, 1950) e um texto do mesmo jornal informa que um "Torneio Inter-Colonial de Atletismo" ocorreria nessa população desde 1931, tendo sido estancada 
no período da guerra e retornado em 1947, em sua décima primeira versão (NO TIETÊ..., 1947).

A respeito da natação, encontramos um evento de grande importância para os colonos japoneses em 1950: a visita dos nadadores nipônicos conhecidos como Peixes Voadores. Essa visita teve grande repercussão no Jornal de Notícias, desde os primeiros rumores sobre o seu acontecimento. Em junho de 1949, um dos dirigentes da Federação Paulista de Natação, Fernando Corrêa da Silva, anunciava que já havia esforços da instituição para trazer os nadadores. Algo significativo nessa entrevista é a referência de Corrêa da Silva a um "estilo japonês" de natação: apesar de não haver, segundo ele, um estilo brasileiro, devido à miscigenação, em Marília “já se nada no estilo japonês, não os descendentes desta raça, como também elementos brasileiros” (EXIBIÇÕES..., 1949). Aqui vemos marcada a associação de uma nacionalidade a uma maneira específica percebida de praticar esse esporte.

O Jornal de Notícias continuava a acompanhar o processo de busca pelos atletas e uma matéria publicada em outubro de 1949 revela que o DEESP estaria planejando trazêlos ao estado de São Paulo, especificamente para o município Marília (NADADORES JAPONESES, 1949). Em fevereiro do ano seguinte, o jornal anunciava que a equipe de nadadores japoneses partiria no mesmo mês para participar do Campeonato Brasileiro de Natação e para realizar apresentações em cidades do interior, opinando que seria "dos maiores o interesse em torno da presença dos recordistas mundiais" (PREPARA-SE..., 1950).

As matérias publicadas no jornal apontam para um envolvimento da colônia japonesa com a chegada de seus patrícios. Por exemplo, foi um "[d] estacado membro da 
colônia japonesa" quem avisou ao Departamento Metropolitano de Natação sobre a data da chegada dos nadadores (DO RIO, 1950). Mais do que isso, o jornal afirmou que, segundo o DEESP, haveria um trabalho conjunto com uma "comissão da colônia japonesa" para elaborar "um grandioso plano de recepções aos grandes 'azes' da natação mundial" (CONFIRMADA..., 1950). Esse envolvimento com a recepção de seus patrícios pode ser bem explicado por um sentimento de afeição nacional. Sendo muitos integrantes da colônia japonesa ainda parte da primeira geração de imigrantes (ou segunda, em menor grau), não são apenas ancestrais longínquos que estão gerando tanto entusiasmo, mas os conterrâneos que há muito não são vistos. É claro que, a bem da verdade, eles provavelmente nunca tinham sido vistos antes. Como percebemos na obra de Anderson, é justamente esse sentimento de comunhão que faz da nação uma comunidade imaginada. Para lembrarmos: a nação é vista como uma comunidade imaginada "porque mesmo os membros da mais minúscula das nações jamais conhecerão, encontrarão, ou sequer ouvirão falar da maioria de seus companheiros, embora todos tenham em mente a imagem viva da comunhão entre eles" (ANDERSON, 2008, p.32). Esse encontro com outros japoneses se torna ainda mais importante pelo fato de que a comunicação dos imigrantes com a sua terra natal ainda não havia sido completamente reestabelecida - as viagens entre Brasil e Japão só seriam retomadas alguns anos depois.

O Jornal de Notícias continua a acompanhar o trajeto dos visitantes, comentando seu itinerário (CHEGAM..., 1950), dando instruções para os imigrantes que acompanhariam sua chegada ao aeroporto (SÃO PAULO RECEBE..., 1950) e cobrindo o evento receptivo (CHEGARAM..., 1950). A seção esportiva do jornal notavelmente apreciava a visita dos Peixes Voadores, assim como era elogiosa em relação aos japoneses 
radicados no Brasil, parecendo não ser negativamente afetada pelas crises na colônia e seu conflito com o Brasil alguns anos antes. Apoiando veementemente a presença dos adorados visitantes, o periódico repudiou a atitude do clube Guanabara no Rio de Janeiro, que estaria impondo dificuldades para a apresentação dos nadadores na capital do país (FAZ..., 1950).

Em meio à euforia do contato com os irmãos de nação, houve também a oportunidade para a propagação de boatos. Um documento traduzido erroneamente fora publicado no jornal Folha da Noite ${ }^{11}$ - tratava-se de uma nota da associação Zenpaku Seinen Renmei, ou Centro da Nova Juventude Brasileira, que originalmente criticava o monopólio de uma parte da colônia japonesa sobre a recepção dos atletas, mas que fora publicada dizendo que a "Nova Brasileira" acusava os visitantes de serem coreanos disfarçados de japoneses (A JUVENTUDE JAPONESA..., 1950). A acusação falsa teria sido motivada pelo fato de que os Peixes Voadores haviam dito, em entrevista, que o Japão de fato perdera a guerra, irritando os associados, mas a nota publicada no jornal desmente a tradução falsa e reitera o prazer dos membros do Centro ao receber os atletas.

Apesar de ser uma farsa, um boato só pode se propagar quando é favorecido pela situação social em que ele está colocado (BLOCH, 2001, p.107). Assim, um boato como esse apenas pôde ser publicado e chamar a atenção do público paulista porque, ainda em 1950, ele soava verossímil aos ouvidos de uma população que vira recentemente os imigrantes japoneses entrar em conflito por conta de seu nacionalismo (que, como vimos, incluía um sentimento de vitorismo). Segundo Miyao e Yamashiro (1992), o que restava do vitorismo japonês teria entrado em inclinada decadência já em 1951, quando alguns imigrantes retornaram ao Japão e viram com os próprios olhos a realidade. Para Dezem

\footnotetext{
${ }^{11}$ Aparece em Lesser (2001).
} 
(2000), essa tensão só se dissiparia após a retomada das imigrações, em 1953. Sabemos que a filial da Shindo-Renmei em Lucélia, SP, sobreviveu até meados de 1950 (MIYAO; YAMASHIRO, 1992) e que, em 1953, ainda a revista Seinen $^{12}$ defendia a atitude dos terroristas da Tokkô-tail ${ }^{13}$. Havia, sem dúvida, bons motivos para que os paulistas em geral, assim como os colonos, encontrassem na publicação algum traço de verossimilhança.

\section{Para Além do Jornal de Notícias}

Apesar de termos feito, como esclarecemos, uma pesquisa sobre as práticas esportivas dos imigrantes japoneses no Jornal de Notícias, não poderíamos deixar de incluir, entre os resultados da nossa busca, dois documentos que, preservados pela transcrição de outros autores, adicionam algo à discussão sobre as relações entre práticas corporais e a identidade nacional desses sujeitos. Um deles é um documento que Miyao e Yamashiro (1992, p.316-7) registraram com o nome de "Plataforma Shindo Renmei". Datado de 22 de julho de 1945, o documento chamava os "súditos do Grande Império do Japão" para o cultivo do "espírito japonês", através do respeito à integridade moral, da concretização do patriotismo e da lealdade ao imperador mediante diligência, esforço, paciência e autoestima. Partindo da premissa de que era próprio aos japoneses contribuir com a construção da Grande Ásia Oriental, chamava para a necessidade de um projeto educacional que colaborasse com a causa.

\footnotetext{
${ }^{12}$ Seikichi KUWABARA. Esperamos muito dos moços. Revista Seinen, $\mathrm{n}^{\circ} 1,1^{\circ}$ de maio de 1953. Trecho transcrito por Miyao e Yamashiro (1992, p.341).

${ }^{13}$ Tokkô-Tai era um subgrupo da Shindo-Renmei. Era o responsável pelas sabotagens e assassinatos ligados aos nacionalistas.
} 
Para nós japoneses residentes no Brasil colaborarmos na construção da Grande Ásia Oriental, devemos primeiramente executar um programa de ensino apropriado para tal fim. Isto é, enaltecer a idéia de reverência aos deuses e de culto aos antepassados, promover a educação física e, para que os nossos filhos se tornem súditos do Império, devemos nos esforçar no ensino da língua japonesa e dedicar esforço à educação moral dos adultos. ${ }^{14}$

Aqui, a promoção da educação física aparece ao lado da reverência aos deuses e do culto aos antepassados como aspecto importante para a construção da Grande Ásia Oriental. Dessa “educação física”, encontramos um vestígio, mostrado a seguir, que sugere que ela estivesse principalmente ligada às artes marciais.

O segundo documento, um manuscrito do diretor-presidente da Shindo Renmei, Junji Kikkawa, revela organogramas das atividades da associação na sede central e nas filiais. O organograma da sede central organizava, sob o comando do Diretor-Presidente e do Diretor-Superintendente, uma "Secretaria geral”, responsável por "assuntos gerais", "propulsão" e "tesouraria", um departamento de "relações externas", com o objetivo de “estreitamento de relações entre o Japão e o Brasil", um departamento de "comunicação", que devia cuidar de assuntos de "imprensa", "correspondência", "lazer e recreação", e, além disso, um departamento de "educação", que deveria conter educação "espiritual", "língua japonesa", "cursos para adultos" e "artes marciais". Em seguida, o organograma das filiais colocava sob a organização do diretor e do vice-diretor também uma secretaria de serviços gerais e um departamento de educação. Este último devia cuidar das mesmas quatro categorias de atividades educativas que apareciam no organograma da sede central, segundo os seguintes objetivos:

\footnotetext{
${ }^{14}$ Plataforma da Shindo Renmei, transcrita por Miyao e Yamashiro (1992, p.316-7). Grifos meus.
} 
Espiritual - procurar difundir o espírito de reverência aos deuses Japonês - cuidado na seleção do professor, orientação e fiscalização Artes Marciais - orientar grupos esportivos

Ed. Adultos - espírito de grupos de vizinhos ${ }^{15}$

Além disso, segundo Nakadate (1988 apud MIYAO; YAMASHIRO, 1992, p.360), a filial da Shindo Renmei de Lucélia, SP, teria sobrevivido até 1950 proporcionando educação livresca e artes marciais a seus associados.

Não dispomos aqui de elementos empíricos para desvendar apropriadamente os significados da prática de educação física artes marciais para os imigrantes japoneses nacionalistas do pós-guerra. Nem mesmo podemos afirmar, com certeza, que as diretrizes encontradas no manuscrito se converteram realmente em ações pela central ou pelas sedes da associação. Mas é significativo o fato de que a maior agremiação nacionalista dos imigrantes japoneses estivesse preocupada com a educação do corpo, com os lazeres esportivos e com a promoção de práticas corporais de origem japonesa, como as artes marciais. Isso aponta, embora reforcemos a necessidade de mais estudos, para a relação buscada entre essas práticas e a manutenção ou o fortalecimento da identidade nacional em solo estrangeiro.

\section{Considerações Finais}

As matérias colhidas no Jornal de Notícias demonstram que os esportes eram presentes na colônia japonesa no período estudado. Muitas vezes, aliás, os japoneses eram destaques nessas práticas, como era o caso do beisebol, difundido no Brasil pela colônia

\footnotetext{
${ }^{15}$ Manuscrito de Junji Kikkawa, presidente da Shindo Renmei, transcrito por Miyao e Yamashiro (1992).
} 
japonesa, e da natação, pelo que eram reconhecidos os nadadores japoneses de Marília. É relevante o fato de que a maioria das notícias veiculadas pelo Jornal de Notícias enfatiza o envolvimento desses imigrantes com os esportes, que são historicamente elaborações europeias.

Há um silêncio das fontes primárias em relação às práticas corporais japonesas que são comumente entendidas como mais icônicas ou representativas do Japão (artes marciais, danças folclóricas, etc.), em contraste com as práticas esportivas, que aparecem insistentemente. Interpretamos que isso ocorre porque estas últimas eram efetivas em integrar os colonos japoneses à sociedade paulista, enquanto as primeiras permaneceram confinadas na colônia, tornando-se inacessíveis ou mesmo desinteressantes aos jornais. Os esportes exigiam dos japoneses uma integração, que se estabelecia na filiação a federações, aquisição licenças para competições, fundação de associações, participação em competições nacionais ou regionais, etc., o que fez com que ficassem naturalmente mais evidentes para um jornal paulista que pôde, com isso, perceber essas práticas no cotidiano das cidades e reportá-las. Esse destino de se tornar visível à comunidade local através do Jornal de Notícias na segunda metade da década de 1940 não foi compartilhado por práticas culturais como o sumô, o kendô, o judô e outras tradições dos usos do corpo entre os japoneses.

Mesmo assim, podemos observar que havia esportes que, independentemente de figurarem ou não no imaginário que lançamos sobre o "mundo oriental", eram tradicionais na colônia. $\mathrm{O}$ beisebol e o atletismo, como vimos anteriormente, foram práticas mantidas pela colônia japonesa desde muito cedo. É preciso, antes de tudo, questionar a rigidez dos usos de "tradicional" e "oriental" para o objeto e o período de que estamos tratando aqui. 
Os esportes tidos como de origem ocidental adentraram o Japão antes que os japoneses emigrassem para o Brasil (MARTA, 2010) e o beisebol, por exemplo, já era um esporte muito praticado pelos japoneses (LIN; LEE, 2007). Por isso, seria um erro entender o "tradicional" apenas como o "exótico". Atletismo, beisebol, natação, e tênis, além de, possivelmente, outros esportes, formavam uma cultura corporal própria da colônia japonesa em São Paulo.

As notícias nos mostram ainda que a colônia se mobilizava não só para a promoção dos esportes entre os aqui radicados, mas também pela visita de esportistas japoneses, como foi o caso dos tenistas e dos nadadores.

Naquilo que diz respeito à relação entre os esportes e a identidade, é imperativo reconhecer que as nossas informações não são muito vastas, mas já nos é possível observar alguns pontos de intersecção. Percebemos que o beisebol tinha íntima ligação com a nacionalidade japonesa, além de ser percebida, através da imprensa, a associação entre os japoneses e um tipo específico de nado. Vimos também que foi através da natação que a colônia japonesa pôde manifestar uma solidariedade nacional para com os atletas pertencentes à mesma comunidade imaginada. Ali, conflitos nacionalistas favoreceram a propagação de boatos. Ainda é preciso perceber que, a partir das fontes de Miyao e Yamashiro (1992) - os documentos da Shindo-Renmei -, para além do que observamos em nosso corpo documental principal, apontam mais precisamente para a relevância de práticas corporais integradas a um sistema institucional de lazer e educação, para afirmação da niponidade, onde se ressaltava a importância das artes marciais e da educação física para um projeto educacional japonês. Conjecturamos que essas práticas, ligadas às representações de Japão, eram importantes para inculcar e fortalecer o sentimento de 
pertencimento a uma comunidade japonesa. Estimamos, por fim, que pesquisas futuras possam elucidar melhor essas questões através de dados empíricos e ampliar os conhecimentos sobre as relações entre práticas corporais e identidade na imigração japonesa.

\section{REFERÊNCIAS}

ANDERSON, Benedict. Comunidades Imaginadas: reflexões sobre a origem e a difusão do nacionalismo. São Paulo: Companhia das letras, 2008.

ATIVIDADES... Atividades tenísticas. Jornal de Notícias, São Paulo, p.11, 5 de agosto de 1950.

BAINER, Alan; HWANG, Dong-Jhy. Representing Taiwan: international sport, ethnicity and national identity in the Republic of China. International Review for the Sociology of Sport, v.46, n.3, p. 231-248, 2010.

BARBOSA, Marialva. História cultural da imprensa: Brasil, 1900-2000. Rio de Janeiro: Mauad X, 2007.

BARTOLOMÉ, Miguel Alberto. El derecho a la existencia cultural alterna. Em: ZARUR, G. C. L. (Org.). Etnia e Nação na América Latina. Washington, D.C., U.S.A.: OEA Organização dos Estados Americanos, p. 25-35, 1994. (Colección INTRAMER, n.44).

BLECKING, Diethelm. Sport and immigration in Germany. The international journal of the History of sport, v.25, n.8, p. 955-973, 2008.

BLOCH, Marc L. B. Apologia da história, ou, o ofício do historiador. Rio de Janeiro: Jorge Zahar, 2001.

BRASIL. Decreto $\mathbf{n}^{\mathbf{0}} \mathbf{1 8 . 8 1 1}$ de 6 de junho de 1945. Disponível em: http://www2.camara.leg.br/legin/fed/decret/1940-1949/decreto-18811-6-junho-1945470887-publicacaooriginal-1-pe.html. Acesso em : 30 out. 2015.

BUNK, Brian. D. Sardinero and not a can of sardines: soccer and Spanish Ethnic Identities in New York City during the 1920. Journal of urban history, v.41, n.3, p. 444-459, 2015.

BURKE, Peter. O que é história cultural? Rio de Janeiro: Jorge Zahar, 2005.

CAMPEONATO... Campeonato de Basebol. Jornal de Notícias, São Paulo, p.10, 22 de março de 1950. 
CAMPOS, Walter de O. Discriminação racial e imprensa no início dos anos 1950: um relato da Lei Afonso Arinos em sua concepção e nascimento. Patrimônio e memória, v. 11, n. 1, p. 283-304, 2015.

A Lei Afonso Arinos e sua repercussão nos jornais (1950-1952): entre a democracia racial e o racismo velado. 2016. 156 f. Tese (Doutorado em História) Faculdade de Ciências e Letras, Universidade Estadual Paulista "Júlio de Mesquita Filho", Assis, 2016.

CAPISTEGUI, Francisco. J. Deporte e identidad, o sobre cómo definirnos. Historia y Comunicación Social, v.17, p. 19-39, 2012.

CARDOSO, Ruth C. L. Estrutura familiar e mobilidade social: estudo dos japoneses no estado de São Paulo. São Paulo: Primus Comunicação, 1995.

CHARTIER, Roger. A história cultural: entre práticas e representações. Rio de Janeiro: Bertrand Brasil, 1988?

CHEGAM... Chegam amanhã os nadadores japoneses. Jornal de Notícias, São Paulo, p.10, 3 de março de 1950 .

CHEGARAM... Chegaram os nadadores japoneses. Jornal de Notícias, São Paulo, p.14, 5 de março de 1950.

CONFIRMADA... Confirmada a vinda dos nadadores japoneses. Jornal de Notícias, São Paulo, p.10, 1 de março de 1950.

DARBY, Paul. Emigrants at play: Gaelic Games and the Irish diaspora in Chicago, 1884c.1900. Sport in History, v.26, n.1, p. 47-63, April 2006.

. Playing for Ireland in foreign fields: the Gaelic Athletic Association and Irish nationalism in America. Irish Studies Review, v.18, n.1, p. 69-89, February 2010a.

- The Gaelic Athletic Association, transnational identities and Irish America. Sociology of Sport Journal, v.27, p.351-370, 2010 b.

DEZEM, Rogério. Shindô-Renmei: terrorismo e repressão. São Paulo: Arquivo do Estado, Imprensa Oficial, 2000. (Inventário Deops, 3).

A DIREÇÃO... A Direção do Jornal de Notícias. Jornal de Notícias, São Paulo, p. 2, 14 de outubro de 1948.

ENNES, Marcelo A. Relações interétnicas: ambiguidades e inacabamento. Perspectivas. São Paulo, v. 26, p. 35-55, 2003. 
ESTABELECIMENTO... Estabelecimento Nacional Indústria de Anilinas S.A. "ENIA". Jornal de Notícias, São Paulo, p. 5, 15 de junho de 1947.

EVANS-PRITCHARD, Edward E. Lévy-Bruhl. In: Antropologia social da religião. Rio de Janeiro: Campus, p. 111-38, 1978.

EXIBIÇÕES... Exibições de Willy Jordan no Japão. Jornal de Notícias, São Paulo, p.10, 3 de junho de 1949.

FAZ... Faz exigências o Guanabara para ceder sua piscina. Jornal de Notícias, São Paulo, p.10, 15 de março de 1950.

O INTERIOR EM REVISTA. O interior em revista. Jornal de Notícias, São Paulo, p.6, 27 de maio de 1950.

JAPONESES VS. NOVOS. Japoneses vs. novos. Jornal de Notícias, São Paulo, p.7, 12 de outubro de 1950.

JOHNSON, Noah C. G. The japanization of Karate?: placing an inteligible cultural practice. Journal of Contemporary Anthropology, v.3, n.1, p. 61-78, 2012.

A JUVENTUDE JAPONESA... A juventude japonesa e os peixes-voadores. Jornal de Notícias, São Paulo, p.12, 23 de março de 1950.

KOIFMAN, Fábio; ODA, Humberto M. A declaração brasileira de guerra ao Japão. SNH SIMPÓSIO NACIONAL DE HISTÓRIA, 27, Anais... Natal, RN: 2013.

LESSER, Jeffrey. A negociação da identidade nacional: imigrantes, minorias e a luta pela etnicidade no Brasil. São Paulo: Editora Unesp, 2001.

LIN, Chien-Yu; LEE, Ping-Chao. Sport as a medium of national resistance: politics and baseball in Taiwan during Japanese colonialism, 1895-1945. The International Journal of the History of Sport, v.24, n.3, p. 319-337, March 2007.

MARTA, Felipe E. F. A memória das lutas: as artes marciais orientais e a sua presença na cultura corporal de São Paulo. São Paulo: EDUC, 2010.

MAUSS, Marcel. Divisão concreta da sociologia. In: Ensaios de sociologia. São Paulo: Perspectiva, p. 57-78, 1999.

MIYAO, Susumu; YAMASHIRO, José. Período em branco na corrente imigratória e os distúrbios na comunidade japonesa. In: SOCIEDADE BRASILEIRA DE CULTURA JAPONESA. Uma epopéia moderna: 80 anos da imigração japonesa no Brasil. São Paulo: Hucitec, p. 247-381, 1992. 
NADADORES JAPONESES. Nadadores japoneses. Jornal de Notícias, São Paulo, p.11, 9 de outubro de 1949.

NAKADATE, Jouji. O Japão venceu os aliados na Segunda Guerra Mundial? O movimento social “Shindo Renmei” em São Paulo (1945-1949). São Paulo: [s.n.], 1988 apud MIYAO, Susumu; YAMASHIRO, José. Período em branco na corrente imigratória e os distúrbios na comunidade japonesa. In: SOCIEDADE BRASILEIRA DE CULTURA JAPONESA. Uma epopéia moderna: 80 anos da imigração japonesa no Brasil. São Paulo: Hucitec, 1992, p.247-381.

NOSSO... Nosso roteiro. Jornal de Notícias, São Paulo, p. 2, 12 de abril de 1946.

NO TIETÊ... No Tietê a disputa do torneio Inter-Colonial de atletismo. Jornal de Notícias, São Paulo, p.8, 20 de setembro de 1947.

NOVOS VS. JAPONESES. Novos vs. japoneses. Jornal de Notícias, São Paulo, p.11, 13 de setembro de 1950 .

PILAGALLO, Oscar. História da imprensa paulista: jornalismo e poder de D. Pedro I a Dilma. São Paulo: Três Estrelas, 2012.

PREPARA-SE... Prepara-se Marilia para receber os azes da aquática japonesa. Jornal de Notícias, São Paulo, p.8, 21 de fevereiro de 1950.

QUITZAU, Evelise A.; SOARES, Carmen L. "A força da juventude garante o futuro de um povo": a educação do corpo no Sport Club Germania (1899-1938). Movimento, v. 16, n. 03, p. 89-108, 2010.

Do Rio. Jornal de Notícias, São Paulo, p. 10, 25 de fevereiro de 1950.

SÃO PAULO RECEBE... São Paulo recebe hoje os nadadores japoneses. Jornal de Notícias, São Paulo, p.10, 4 de março de 1950.

O SR. ADHEMAR... O Sr. Adhemar de Barros foi reeleito para a presidência nacional do P.S.P. Jornal de Notícias, São Paulo, p. 3, 17 de julho de 1947.

SEYFERTH, Giralda. Os imigrantes e a campanha de nacionalização do Estado Novo. In: PANDOLFI, Dulce (Org.). Repensando o Estado Novo. Rio de Janeiro: FGV, p.199-228, 1999.

TRABALHA-SE... Trabalha-se em São Paulo para a maior difusão do base-ball. Jornal de Notícias, São Paulo, p.8, 16 de fevereiro de 1947.

VAI AO JAPÃO... Vai ao Japão o diretor do DEESP. Jornal de Notícias, São Paulo, p. 9, 7 de outubro de 1950. 
SILVA, Ana M. Entre o corpo e as práticas corporais. Arquivos em movimento. Rio de Janeiro, v.10, n.1, p. 5-20, 2014.

SILVA, Carolina F.; PEREIRA, Ester L.; MAZO, Janice Z. Clubes sociais: práticas esportivas e identidades culturais. Licere, v. 15, n. 02, p.1-21, 2012.

SILVA, Carolina F. et al. Associações de remadores teuto-brasileiros em Porto Alegre (1917): Recomposições identitárias em um conflito bélico. J. Phys. Educ., v. 27, p. 1-12, 2016.

SODRÉ, Nelson W. História da imprensa no Brasil. Rio de Janeiro. Mauad, 1999.

VIEIRA, Francisca. O japonês na frente da expansão paulista: o processo de absorção do japonês em Marília. São Paulo, Pioneira, EDUSP, 1973 apud DEZEM, Rogério. ShindôRenmei: terrorismo e repressão. São Paulo: Arquivo do Estado, Imprensa Oficial, 2000.

\section{Endereço dos Autores:}

Igor Cavalcante Doi

Faculdade de Educação Física da Unicamp

Av. Érico Veríssimo, 701 Cidade Universitária

Campinas - SP - 13.083-851

Endereço eletrônico: igorcavalcantedoi@gmail.com

Edivaldo Góis Junior

Faculdade de Educação Física da Unicamp

Av. Érico Veríssimo, 701 Cidade Universitária

Campinas - SP -13.083-851

Endereço eletrônico: egoisjunior@gmail.com 